PAPER

\title{
The effect of treatment upon temporal dispersion in Ivlg responsive multifocal motor neuropathy
}

\author{
A Ghosh, A Virgincar, R Kennett, M Busby, M Donaghy
}

J Neurol Neurosurg Psychiatry 2005;76:1269-1272. doi: 10.1136/jnnp.2004.050252

See end of article for authors' affiliations .....................

Correspondence to: Dr Michael Donaghy, Department of Clinical Neurology, Radcliffe Infirmary, Oxford OX2 $6 \mathrm{HE}, \mathrm{UK}$; joanna.wilkinson@ clneuro.ox.ac.uk

Received 22 July 2004 Revised version received 24 February 2005 Accepted 28 March 2005

\begin{abstract}
Background: Multifocal motor neuropathy with conduction block ( $M M N)$ is a treatable disorder that can be mistaken for other lower motor neurone syndromes. Existing electrophysiological diagnostic criteria for $M M N$ are restrictive. In particular, many are cautious about diagnosing conduction block (CB) in the presence of abnormal temporal dispersion (TD).

Objective: To study the significance of TD in $M M N$, its relationship to $C B$ in intravenous immunoglobulin (lvlg) responsive patients, and its utility in detecting a treatment response.

Methods: We compared pre- and post-treatment changes in CB and TD in nine patients who satisfied clinical and electrophysiological criteria for $M M N$ and responded to Ivlg.

Results: TD improved in one or more nerve segments in eight of nine patients tested. There was marked improvement in $65 \%$ of all nerve segments, and $60 \%$ of those segments with CB. By comparison, significant improvement in $\mathrm{CB}$ occurred in only $33 \%$ of segments. Of segments with significantly better $\mathrm{CB}$ after treatment, all but one showed similar improvements in TD. Such changes were not related to the degree of TD before treatment, being seen in segments with abnormal as well as normal TD. There was no correlation between improvements seen in TD and CB.

Conclusion: We believe that TD should be considered an inherent feature of MMN. Improvement in TD is an independent marker of electrophysiological improvement in this disorder and is likely to be more useful than $C B$. When MMN is clinically suspected, the use of stringent criteria for $C B$ in the presence of TD should be avoided.
\end{abstract}

M ultifocal motor neuropathy with conduction block $(\mathrm{MMN})$ is a relatively rare disorder characterised by slowly progressive, asymmetrical, lower motor neurone weakness usually starting in the arms with minimal or no sensory symptoms. ${ }^{1}$ Treatment with intravenous immunoglobulin (IvIg) $)^{2-7}$ or cyclophosphamide ${ }^{8-10}$ or both $^{5}{ }^{11}$ results in clinical improvement. Correct differentiation of this treatable condition from other motor neurone diseases is crucial. The electrophysiological hallmark of MMN is conduction block (CB). ${ }^{912-20}$ A major obstacle to the satisfactory definition of $\mathrm{CB}$ has been the presence of temporal dispersion (TD). This can produce an apparent, but misleading, drop in the proximal CMAP (compound motor action potential) amplitude through a process of interphase cancellation. ${ }^{13}$ Most definitions of CB either do not accommodate TD or demand even more stringent criteria in its presence. Potentially this reduces the value of nerve conduction studies in detecting this potentially treatable disorder. ${ }^{21}$ The occurrence of TD has been noted in MMN patients. ${ }^{14} 162223$ Whilst a variety of alterations in CB have been documented in MMN following IvIg, ${ }^{71} 1422$ 24-26 there are no systematic studies of changes in TD, and their correlation with clinical benefit, following effective treatment with IvIg.

\section{METHODS}

This study looked at pre- and post-IvIg changes in TD in patients who satisfied clinical and electrophysiological criteria for MMN and who responded clinically to IvIg. All patients had chronic, progressive, asymmetric motor neuropathy, no upper motor neurone signs, and CB at one or more motor nerve segments separate from common sites of nerve compression. A neurologist with experience in assessing peripheral nerve disorders ( $\mathrm{MD}$ or AG) performed the clinical observations. An improvement of the MRC score by at least one grade in one or more affected muscle groups or a self assessed functional performance score by at least one grade (normal>independent but with difficulty $>$ performs with help $>$ cannot perform) in $\geqslant 30 \%$ of affected tasks was taken as a positive clinical outcome following treatment. Post-IvIg clinical and electrophysiological assessments were made between 2 and 4 weeks after treatment.

Much of the neurophysiological data was analysed retrospectively and the nerves tested post-IvIg tended to be those with known CB (fig 1). CB, in the context of MMN, was defined as a distal to proximal reduction in negative peak CMAP area $>23 \%$ across the distal segment and $>29 \%$ across the proximal segment or in negative peak amplitude $>32 \%$ for the distal segment and $>33 \%$ for the proximal segment. ${ }^{21}$ Abnormal TD is an inappropriate increase in duration of CMAP following proximal stimulation of a nerve when compared to distal stimulation. For our study, abnormal TD was defined as an increase in negative peak duration of CMAP $>37 \%$ (mean \pm 3 SD over healthy controls), although the definition of $\mathrm{CB}$ was not affected by TD. ${ }^{21}$ Percentage changes in $\mathrm{CB}$ following treatment were calculated according to the formula ( $\mathrm{CB}$ before treatment $-\mathrm{CB}$ after treatment)/CB before treatment $\times 100 \% .{ }^{14}$ Changes in TD were also calculated using a similar formula, that is (TD before treatment-TD after treatment)/TD before treatment $\times 100 \%$.

Although there is uncertainty regarding what constitutes clinically meaningful change in pre- and post-treatment values in $\mathrm{CB}$ and $\mathrm{TD}$, we considered a $>20 \%$ improvement to be significant for both. ${ }^{14}$

Abbreviations: $\mathrm{CB}$, conduction block; $\mathrm{CMAP}$, compound motor action potential; Ivlg, intravenous immunoglobulin; MMN, multifocal motor neuropathy with conduction block; TD, temporal dispersion 

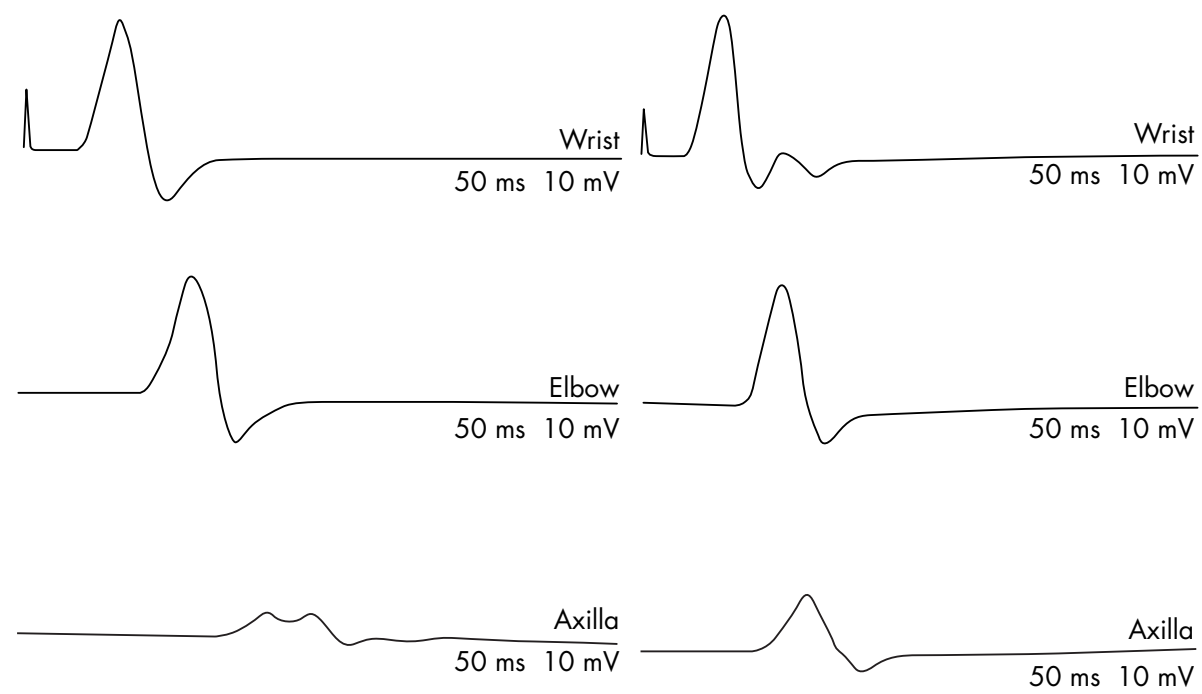

Figure 1 Compound muscle action potential amplitudes recorded from abductor pollicis brevis before and 2 weeks after Ivlg treatment. Changes in amplitude and duration are shown following median nerve stimulation at the wrist, elbow, and axilla.

\section{Statistics}

We used non-parametric statistical methods. Spearman correlation coefficient was used to assess correlation between the improvement of TD and of $\mathrm{CB}$.

\section{RESULTS}

Pre- and post-treatment data on TD were available in nine patients (seven male and two female; age of onset 2767 years; median 40 years). Thirteen nerves with $\mathrm{CB}$ in at least one segment were studied. Data on TD were available from 15 nerve segments with $\mathrm{CB}$ but also from five other segments without CB (table 1).

TD lessened in one or more nerve segments in eight of nine patients tested. This occurred irrespective of whether the pretreatment TD was prolonged or within the normal range. In all, 15 of the 20 segments showed some improvement in TD; 11 of these were in regions showing CB. TD improved by $>20 \%$ of the pre-treatment values in 13 segments $(65 \%)$. The actual improvements were $>30 \%$ in all these segments. Nine of the 13 segments were in areas of pre-treatment $\mathrm{CB}$ and four of the nine segments showed a significant, that is $>20 \%$, improvement in CB. ${ }^{14}$

We assessed separately the effect of treatment on abnormal TD. We tested response using three different values for abnormal TD, namely $>37 \%,{ }^{21}>30 \%,{ }^{27}{ }^{28}$ and $>15 \% .^{14}{ }^{29}$ Abnormal TD at most sites either disappeared or improved by at least $30 \%$ of its pre-treatment value, whichever criterion was used (table 2). Only one segment showed an increase in TD following treatment.

Of the 15 segments with $\mathrm{CB}$, only five segments showed a $>20 \%$ improvement in the block. Four out of the five segments also showed $>30 \%$ reductions in TD including one segment with a pre-treatment TD value in the normal range. CB disappeared in two nerves.

Six segments with pre-treatment $\mathrm{CB}$ showed neither significant reduction nor worsening of TD following IvIg. Significant improvement in CB was seen in only one of these six segments.

Distal CMAP amplitudes improved by $30 \%$ or more after treatment in three out of the 13 segments studied, and worsened by a similar degree in one patient.

\section{DISCUSSION}

Most of the electrophysiological interest in MMN has focussed upon $\mathrm{CB}$, with the significance of TD largely unexplored. This study emphasises the occurrence of TD in MMN patients and demonstrates that successful treatment of MMN produces more widespread improvements in TD than in $\mathrm{CB}$.

The relation between TD of a CMAP and a drop in CMAP area is complex. Interphase cancellation, compounded by polyphasic motor units, is a recognised mechanism by which TD can reduce CMAP area and hence mimic $\mathrm{CB}^{13}$ Consequently, many have been cautious about diagnosing CB when there is abnormal TD in the same segment. ${ }^{13} 14202729$ In reality, the changes seen in CMAPs are likely to depend, among other factors, upon the relative balance between delay and block of axonal conduction among the faster and slower conducting fibres. Thus, disproportionate slowing along the slower conducting fibres could contribute to TD but produce little change in amplitude. Blocking axonal conduction predominantly through smaller fibres as opposed to the faster conducting fibres could produce lesser reduction in CMAP amplitude and a shorter CMAP duration. On the other hand, a non-uniform slowing of conduction (without actual block of axonal conduction) through the faster conducting fibres could lead to increased interphase cancellation and therefore pseudo-CB with or without $\mathrm{TD}^{13}$ while complete block through these same fibres would produce true CB. As it is not known which subpopulations of nerve fibres are affected by each process, and as non-uniform slowing and $\mathrm{CB}$ are likely to occur simultaneously, it may be difficult to quantify the true degree of $\mathrm{CB}$ from CMAP recordings. These complex interactions may explain why the degree of measurable CB often does not improve despite obvious clinical benefit following IvIg treatment. We believe $\mathrm{TD}$ is just as much an inherent electrophysiological feature of $\mathrm{MMN}$ as $\mathrm{CB}$, and that its measurement may avoid these complex uncertainties in quantifying CB.

Previous studies have investigated improvement in CB as a possible electrophysiological marker of clinical improvement in $\mathrm{MMN}$ and found inconsistent results. ${ }^{2}{ }^{22}{ }^{30}$ In our study, changes in TD were independent of any change in $\mathrm{CB}$ 
Table 1 Pre- and post-treatment changes in conduction block (CB) and temporal dispersion (TD)

\begin{tabular}{|c|c|c|c|c|c|c|c|c|c|c|}
\hline \multirow[b]{2}{*}{$\begin{array}{l}\text { Patient } \\
\text { No. }\end{array}$} & \multirow[b]{2}{*}{ Nerve } & \multirow[b]{2}{*}{ Segment } & \multicolumn{2}{|c|}{ Distal CMAP amplitude } & \multicolumn{3}{|l|}{ TD } & \multicolumn{3}{|l|}{ CB } \\
\hline & & & $\begin{array}{l}\text { Pre-Ivlg } \\
\text { (mV) }\end{array}$ & $\begin{array}{l}\text { Post-lvlg } \\
\text { (mV) }\end{array}$ & $\begin{array}{l}\text { Pre-Ivlg } \\
\text { (\%) }\end{array}$ & $\begin{array}{l}\text { Post-lvlg } \\
\text { (\%) }\end{array}$ & $\begin{array}{l}\text { Befter } \\
(\%)\end{array}$ & $\begin{array}{l}\text { Pre-lvig } \\
(\%)\end{array}$ & $\begin{array}{l}\text { Post-Ivlg } \\
\text { (\%) }\end{array}$ & $\begin{array}{l}\text { Better } \\
(\%)\end{array}$ \\
\hline \multirow[t]{2}{*}{1} & $\mathrm{RU}$ & D & 4.9 & 16.3 & 12 & 11 & 8 & 41 & 35 & 15 \\
\hline & LU & D & 13.4 & 4.9 & 13 & -18 & 238 & 32 & 41 & -43 \\
\hline \multirow[t]{2}{*}{2} & RM & D & 18.3 & 18.5 & 4.6 & -8.8 & 291 & No & - & - \\
\hline & & $P$ & & & 81.2 & 24.8 & 69 & 78.7 & 49.4 & 37 \\
\hline 3 & RU & D & 8.0 & 7.4 & 12 & 7.9 & 34 & 60.7 & 13.9 & 77 \\
\hline \multirow[t]{2}{*}{4} & $\mathrm{RM}$ & D & 12.1 & 9.7 & 28.6 & 40 & -40 & 73.9 & 70.6 & 4 \\
\hline & & $\mathrm{p}$ & & & 23.7 & 7.1 & 70 & No & - & - \\
\hline \multirow[t]{2}{*}{5} & $R M$ & D & 10.5 & 15.5 & 171 & 99 & 42 & 52.3 & 56.7 & -8 \\
\hline & RU & D & 14.0 & 13.5 & 180 & 115 & 36 & 78.6 & 69.6 & 11 \\
\hline \multirow[t]{4}{*}{6} & LU & D & 7.0 & 7.0 & 48.4 & 31 & 36 & 37 & 26 & 30 \\
\hline & & $\mathrm{P}$ & & & 6.3 & 0 & 100 & No & - & - \\
\hline & & $\mathrm{P}$ & & & 2 & 4 & -100 & 34 & 14 & 41 \\
\hline & $\mathrm{RM}$ & D & 8.9 & 11.9 & 11.6 & 4 & 65 & 60.7 & 54.6 & 10 \\
\hline \multirow[t]{4}{*}{7} & $\mathrm{RM}$ & D & 11.5 & 8.3 & 16.4 & -5.4 & 132 & 26 & 21.9 & 16 \\
\hline & & $\mathrm{P}$ & & & 6.2 & 11.5 & -85 & No & - & \\
\hline & RU & D & 5.5 & 4.6 & 96.7 & 90 & 7 & 64.3 & 63 & 2 \\
\hline & & $\mathrm{P}$ & & & 0.1 & -12.7 & 128 & No & - & - \\
\hline \multirow[t]{2}{*}{8} & $R M$ & D & 13.8 & 13.0 & -8.4 & 6.4 & -176 & 81.4 & 65.8 & 19 \\
\hline & & $\mathrm{P}$ & & & 97.4 & 2.4 & 98 & 44.8 & 25.7 & 43 \\
\hline 9 & LM & D & 7.3 & 7.7 & -32 & 9.1 & -128 & 65.7 & 59.7 & 9 \\
\hline
\end{tabular}

(correlation coefficient $=0.103, p=0.72$ ) and occurred twice as frequently. Marked improvements in TD were seen in 65\% of all nerve segments and $60 \%$ of those segments with CB. This compares to only $33 \%$ of segments showing significantly better $\mathrm{CB}$, or $23 \%$ with increased CMAP amplitudes, after IvIg. On the other hand, all but one segment with significantly better $\mathrm{CB}$ after treatment also showed similar improvements in TD. Such reductions were not related to the degree of TD before treatment, being seen in segments with abnormal as well as normal TD. Changes in TD or CB in the distal segment did not correlate with changes in the distal CMAP amplitudes.

Successful treatment of MMN is likely to produce alterations in conduction through the various subpopulations of axons leading to a spectrum of changes, as was seen in our study. TD depends on slowing of conduction across a segment. Improved conduction either through faster or slower conducting fibres could improve TD. An improvement in $\mathrm{CB}$, on the other hand, is largely dependent on the response of fast conducting fibres. Also, unlike pseudo-CB, pseudo-TD does not occur as long as the distal CMAP amplitude is not too small. Out of the 15 segments with CB, six showed neither improvement nor worsening of TD despite clinical improvement. This too can be explained by differential recovery among axons, including the phenomenon of newly unblocked axons still conducting slowly. That five out of these six segments also showed no significant improvement in the CB may reflect new interphase cancellations.

An improvement in muscle strength reflects reduced $\mathrm{CB}$ rather than increased conduction velocity in those slow conducting fibres particularly contributing to TD. Our

Table 2 Post-treatment changes in segments with abnormal TD only (by using different criteria)

\begin{tabular}{llll}
\hline & $\Delta$ TD $>\mathbf{3 7 \%}$ & $\boldsymbol{\Delta T D}>\mathbf{3 0} \%$ & $\mathbf{\Delta T D}>\mathbf{1 5 \%}$ \\
\hline Abnormal TD & 6 & 6 & 9 \\
TD disappeared & 3 & 2 & 3 \\
TD still abnormal but & 2 & 3 & 4 \\
better by $>30 \%$ & 1 & 1 & 1 \\
TD worse post-IVIG & 1 & & \\
\hline
\end{tabular}

findings imply that whilst treatment reverses $\mathrm{CB}$ in some fibres, detection of this is masked by the complex contribution made to the CMAP profile by individual subgroups of motor fibres. From this retrospective study we conclude that TD is an important and independent part of the electrophysiological definition of MMN. When MMN is suspected clinically, the use of stringent criteria for CB in the presence of TD should be avoided. Improvement in TD seems to be a more sensitive marker of electrophysiological improvement than $\mathrm{CB}$.

\section{Authors' affiliations}

A Ghosh, M Busby, M Donaghy, Department of Clinical Neurology, University of Oxford, Radcliffe Infirmary, Oxford OX2 6HE, UK A Virgincar, R Kennett, Department of Clinical Neurophysiology, Radcliffe Infirmary, Oxford OX2 6HE, UK

Competing interests: none declared

\section{REFERENCES}

1 Roth G, Rohr J, Magistris MR, et al. Motor neuropathy with proximal multifocal persistent conduction block, fasciculations and myokymia. Evolution to tetraplegia. Eur Neurol 1986:25:416-23.

2 Kaji R, Shibasaki H, Kimura J. Multifocal demyelinating motor neuropathy: cranial nerve involvement and immunoglobulin therapy. Neurology 1992:42:506-9.

3 Chaudhry V, Corse AM, Cornblath DR, et al. Multifocal motor neuropathy: response to human immune globulin. Ann Neurol 1993;33:237-42.

4 Donaghy M, Mills KR, Boniface SJ, et al. Pure motor demyelinating neuropathy: deterioration after steroid treatment and improvement with intravenous immunoglobulin. I Neurol Neurosurg Psychiatry 1994;57:778-83.

5 Van den Berg LH, Kerkhoff H, Oey PL, et al. Treatment of multifocal motor neuropathy with high dose intravenous immunoglobulins: a double blind, placebo controlled study. J Neurol Neurosurg Psychiatry 1995:59:248-52.

6 Van den Berg-Vos RM, Franssen H, Wokke JH, et al. Multifocal motor neuropathy: diagnostic criteria that predict the response to immunoglobulin treatment. Ann Neurol 2000;48:919-26.

7 Federico P, Zochodne DW, Hahn AF, et al. Multifocal motor neuropathy improved by IVlg: randomized, double-blind, placebo-controlled study. Neurology 2000;55:1256-62.

8 Pestronk A, Cornblath DR, llyas AA, et al. A treatable multifocal motor neuropathy with antibodies to GM1 ganglioside. Ann Neurol 1988;24:73-8.

9 Krarup C, Stewart JD, Sumner AJ, et al. A syndrome of asymmetric limb weakness with motor conduction block. Neurology 1990;40:118-27.

10 Feldman EL, Bromberg MB, Albers JW, et al. Immunosuppressive treatment in multifocal motor neuropathy. Ann Neurol 1991;30:397-401.

11 Nobile-Orazio E, Meucci N, Barbieri S, et al. High-dose intravenous immunoglobulin therapy in multifocal motor neuropathy. Neurology 1993;43:537-44. 
12 Cornblath DR, Sumner AJ, Daube J, et al. Conduction block in clinical practice. Muscle Nerve 1991;14:869-71; discussion 867-8.

13 Rhee EK, England JD, Sumner AJ. A computer simulation of conduction block: effects produced by actual block versus interphase cancellation. Ann Neurol 1990;28:146-56.

14 Chaudhry V, Corse AM, Cornblath DR, ef al. Multifocal motor neuropathy: electrodiagnostic features. Muscle Nerve 1994;17:198-205.

15 Oh SJ, Kim DE, Kuruoglu HR. What is the best diagnostic index of conduction block and temporal dispersion? Muscle Nerve 1994;17:489-93.

16 Katz JS, Wolfe GI, Bryan WW, et al. Electrophysiologic findings in multifocal motor neuropathy. Neurology 1997;48:700-7.

17 Cappellari A, Nobile-Orazio E, Meucci N, et al. Criteria for early detection of conduction block in multifocal motor neuropathy (MMN): a study based on control populations and follow-up of MMN patients. J Neurol 1997;244:625-30.

18 Sumner AJ. Consensus criteria for the diagnosis of partial conduction block and multifocal motor neuropathy. In: Kimura J, Kaji R, eds. Physiology of ALS and related diseases. Amsterdam: Elsevier, 1997:221-7.

19 Olney R. Consensus criteria for the diagnosis of partial conduction block. Muscle Nerve 1999;22:S225-9.

20 Taylor BV, Wright RA, Harper CM, et al. Natural history of 46 patients with multifocal motor neuropathy with conduction block. Muscle Nerve 2000;23:900-8.

21 Ghosh A, Busby M, Kennett R, et al. A practical definition of conduction block in Ivlg responsive multifocal motor neuropathy. J Neurol Neurosurg Psychiatry 2005;76:1264-8.
22 Comi G, Amadio S, Galardi G, et al. Clinical and neurophysiological assessment of immunoglobulin therapy in five patients with multifocal motor neuropathy. J Neurol Neurosurg Psychiatry 1994;57(Suppl):35-7.

23 Saperstein DS, Katz JS, Amato AA, et al. Clinical spectrum of chronic acquired demyelinating polyneuropathies. Muscle Nerve 2001;24:311-24.

24 Meucci N, Cappellari A, Barbieri S, et al. Long term effect of intravenous immunoglobulins and oral cyclophosphamide in multifocal motor neuropathy. J Neurol Neurosurg Psychiatry 1997;63:765-9.

25 Vucic S, Black KR, Chong PS, et al. Multifocal motor neuropathy: decrease in conduction blocks and reinnervation with long-term IVlg. Neurology 2004;63:1264-9.

26 Van den Berg-Vos RM, Franssen H, Wokke JH, et al. Multifocal motor neuropathy: long-term clinical and electrophysiological assessment of intravenous immunoglobulin maintenance treatment. Brain 2002; 125:1875-86.

27 Lange DJ, Trojaborg W, Latov N, et al. Multifocal motor neuropathy with conduction block: is it a distinct clinical entity? Neurology 1992:42:497-505.

28 Bouche $\mathbf{P}$, Moulonguet A, Younes-Chennoufi AB, et al. Multifocal motor neuropathy with conduction block: a study of 24 patients. J Neurol Neurosurg Psychiatry 1995;59:38-44.

29 Brown WF, Feasby TE. Conduction block and denervation in Guillain-Barre polyneuropathy. Brain 1984;107:219-39.

30 Azulay JP, Blin O, Pouget J, et al. Intravenous immunoglobulin treatment in patients with motor neuron syndromes associated with anti-GMI antibodies: a double-blind, placebo-controlled study. Neurology 1994;44:429-32. 